\title{
Right Ulnar Reconstruction after Sequestrectomy by Non-Vascularized Fibular Transfer in a Girl of Three Years
}

\author{
Missoki Azanlédji Boume1, Kwami Edem Edoh Bikor², Yawa Sesime Sanni², \\ Nguefack Blanchard Noumedem², Cynthia Evlo², Vanessa Akakpo², \\ Gamédzi Komlatsè Akakpo-Numado²
}

${ }^{1}$ Pediatric Surgery Department in Kara Teaching Hospital, Kara, Togo

${ }^{2}$ Pediatric Surgery Department in Campus Teaching Hospital, Lomé, Togo

Email: bmissoki@yahoo.fr, missokiboume@gmail.com

How to cite this paper: Boume, M.A., Bikor, K.E.E., Sanni, Y.S., Noumedem, N.B., Evlo, C., Akakpo, V. and Akakpo-Numado, G.K. (2021) Right Ulnar Reconstruction after Sequestrectomy by Non-Vascularized Fibular Transfer in a Girl of Three Years. Open Journal of Orthopedics, 11, 73-84. https://doi.org/10.4236/ojo.2021.113008

Received: January 10, 2021

Accepted: March 14, 2021

Published: March 17, 2021

Copyright $\odot 2021$ by author(s) and Scientific Research Publishing Inc. This work is licensed under the Creative Commons Attribution International License (CC BY 4.0).

http://creativecommons.org/licenses/by/4.0/

(c) (i) Open Access

\begin{abstract}
Chronic osteomyelitis is serious because of the orthopedic sequels that they could cause. Extended diaphyseal sequestrations could cause bone loss and their management is delicate. Here we report a case of right ulnar diaphyseal reconstruction by non-vascularized fibula transfer. This was a three-year-old girl, non-sickle cell, who had chronic osteomyelitis of the right ulna. The evolution was towards an almost total ulnar diaphyseal sequestration with externalization of the distal extremity. The removal of this large sequestrum occurred almost spontaneously, leaving a significant bone loss over a length of about $6 \mathrm{~cm}$. Secondarily, we reconstructed the right ulnar diaphysis by transfer of a free non-vascularized graft of the left fibula, maintained by a pin. The follow up was favorable with almost complete recovery of prono-supination. Fibular ossification has evolved as well and we did not notice any complications at the graft collection site. Non-vascularized fibula graft transfer is a useful therapeutic option in the management of significant bone defects secondary to chronic osteomyelitis of one of the two forearm bones.
\end{abstract}

\section{Keywords}

Free Fibula Transfer, Chronic Osteomyelitis, Ulna, Child, Togo

\section{Introduction}

In contrast to the industrialized countries, chronic osteomyelitis is seen much more frequently in developing countries and places a significant burden on their health services [1]-[7]. In Uganda [8], 3.5\% of surgical procedures in children 
were for osteomyelitis, and $60 \%$ of these procedures were a sequestrectomy. A specialist orthopaedic hospital in Malawi reported that $6.7 \%$ of all orthopaedic procedures in children were for chronic osteomyelitis, the majority being a sequestrectomy [9]. Tekou [10] then Akakpo-Numado [11] reported respectively 77.24\% and 59.38\% of chronic osteomyelitis in hospital series in Lomé (Togo).

Chronic osteomyelitis in children is serious because of the orthopedic sequels that they could cause [9]. One of the delicate sequels is the bone loss, often caused by extended diaphyseal sequestrations [12]. Bone losses cause important management problem [13] [14]. Several surgical methods have been described for bone reconstruction both in the upper limb and in the lower one: cancellous bone graft, Ilizarov's bone distraction [15] or single-stup fibula transfer [13] [14] [16] [17] [18] [19]. The free fibula transfer is one of the most used for bone defects over $2 \mathrm{~cm}$. In West Africa literature we didn't found study on ulna reconstruction by fibula transfer. We here report the first case of ulna reconstruction in a child by free non-vascularized fibula transfer Togo.

\section{Case Report}

Here was the case of a three years old girl, leaving in Kpalimé (Togo) with here patents, who spontaneously presented a right forearm painful swelling in May of 2010. Traditional care was unsuccessful. Two weeks later, suppuration appeared on upper third of the forearm and a fluctuation zone on the wrist. After multiple episodes of suppuration, the girl was admitted to the regional medical center of Lomé, six months after the beginning of symptoms. The right forearm $\mathrm{x}$-ray confirmed chronic osteomyelitis of the ulna, with double pathologic fracture and a big sequester of the ulna shaft. She underwent at the regional medical center, an antibiotic therapy, based on amoxicillin and clavulanic acid association for 7 days, unsuccessfully. She therefore was transferred to the pediatric surgery department of Sylvanus Olympio teaching hospital on the January $20^{\text {th }}$ of 2011, eight months after le onset of the symptoms.

No personal or familial pathologic background was known.

At admission, she didn't have fever. We noted forearm swelling and double suppuration sit, one on the upper third and the other on the lower third. The distal extremity of sequester was externalized by the lower third fistula. Cytobacteriological examination of the pus was negative. Hemoglobin electrophoresis was AA. Once again, the right forearm $\mathrm{x}$-ray confirmed chronic osteomyelitis of the right ulna with double fracture at the either side of a big sequesters (Figure 1).

Sequestrectomy was realized on the 21st of January 2011. During the procedure, we realized that sequester was almost spontaneously removed, and we thoroughly washed the sequester sit and closed the skin by sutures over a drain. The intravenous antibiotic therapy associated ceftriaxone and gentamicin for ten days. Post-operative follow up were uneventful. The girl left hospital ten days after the sequestrectomy under Ciprofloxacin per os. 


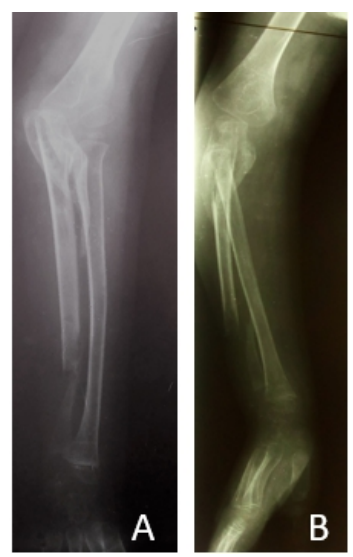

Figure 1. Chronic osteomyelitis of the right ulna with double fracture at the either side of a big sequester: $\mathrm{A}=$ front view, $\mathrm{B}=$ side view.

Three months after the intervention, clinical examination noticed elbow movements conserved, good wound healing and no fistula recurrence. The right forearm $\mathrm{x}$-ray control noted $6 \mathrm{~cm}$ bone loss of ulna shaft with subluxation of condylo-radial join (Figure 2(a)).

We then proceeded to ulnar reconstruction by non-vascularized free graft fibular transfer. The fibular graft was contained by an intramedullary pin, going from one end of the ulna, passing through the medullary canal of the graft (Figure 2(b)). Condylo-radial join was reduced and maintained by a pin. Post-operative follow up was eventful. X-ray controls had been realized immediately, at 3 months and at 21 months after the intervention. At that last $\mathrm{x}$-ray control, there was sufficient callus on the ulna and we had removed its pin. The radial pin which was not in a correct position was also removed at the same time. There is no infection, non-union or rejection of the graft after the operation. Fourty months after the intervention, the callus was well remodeled with good incorporation of the graft and the medullary canal was clearly individualized. However, at the junction of the graft and the proximal fragment of the ulna, an angulation of twenty degrees with lateral apex was observed; that led to a subluxation of the radial head. Many other x-ray controls were realized and noticed the same results (Figure 3 ).

At the various checks, the graft collection sit was in ossification, but this ossification had gradually taken place in a double longitudinal bone structure separated by a free space.

Clinically, nine years after the ulna reconstruction, the examination reported very good functional use of the right elbow with either flexion and extension or supination and pronation degrees comparable to the left side (Figure 4).

Very satisfy joint amplitudes are reported in Table 1.

\section{Discussion}

The forearm bones loss is rare in young children in routine practice. If not managed, it causes unequal length of the two forearm bones, leading to functional 


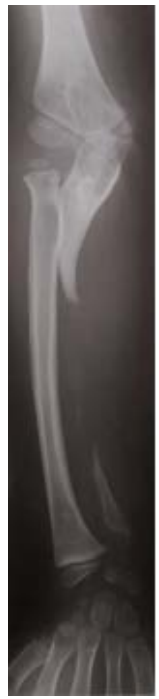

(A)

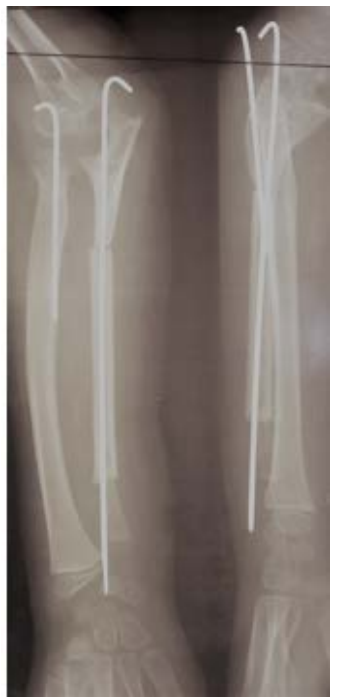

(B)

Figure 2. Right forearm x-ray control noted $6 \mathrm{~cm}$ bone loss of ulna shaft with subluxation of condylo-radial join (A) and ulnar reconstruction by non-vascularized free graft fibular transfer contained by an intramedullary pin (B).

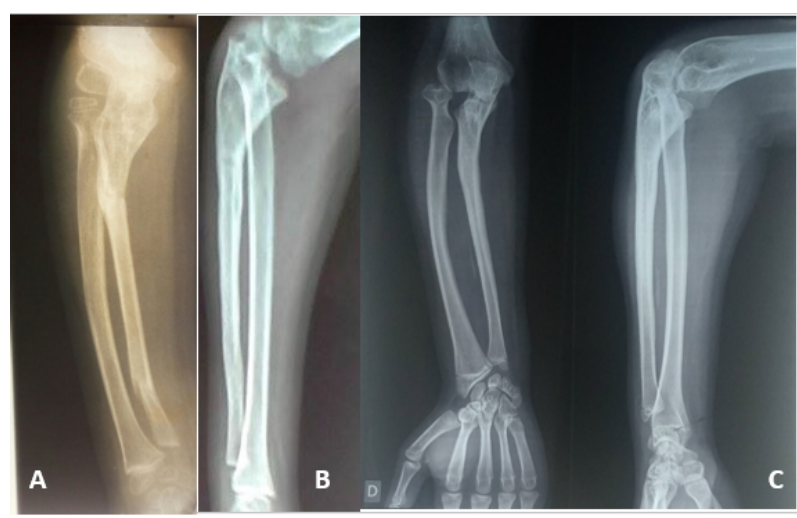

Figure 3. X-ray controls 2 years (A), 3 years (B) and 9 years (C) after reconstruction.

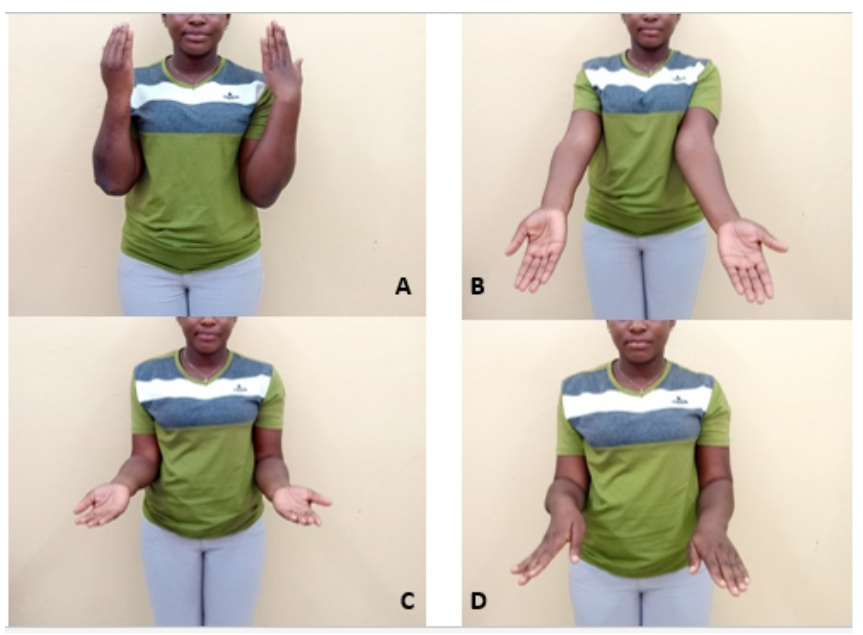

Figure 4. Functional use of the right elbow with either flexion and extension or supination and pronation degrees comparable to the left side. 
Table 1. The range of motion at nine years after operation.

\begin{tabular}{ccc}
\hline & Right side (operated) & Left side \\
\hline Elbow extension & $0^{\circ}$ & $10^{\circ}$ \\
Elbow flexion & $150^{\circ}$ & $150^{\circ}$ \\
Pronation & $160^{\circ}$ & $180^{\circ}$ \\
Suppination & $0^{\circ}$ & $0^{\circ}$ \\
\hline
\end{tabular}

damage of the elbow and also involving pro-supination. These two consequences were particularly serious for this three-year-old girl. The aim of our work was to show a possibility of reconstruction of bones losses in children, even under the conditions of limited equipment which characterize the developing countries. We did not find in the literature, cases of free transfer of fibula to the ulna in children in the West African sub-region. This is the first case reported in the literature in Togo.

The literature is indeed abundant in terms of free fibula transfer, in carcinological [20] [21] [22]; stomatological [23] [24] [25] [26] [27], and orthopedic [16] [28]-[37] surgeries. The fibula allows reconstruction of long bone defects beyond $5 \mathrm{~cm}$, especially if the vascular condition of the seat is poor [17]. In these indications, it has proven its superiority over other conventional reconstruction methods using cancellous grafts [17]. Fibula transfers are indicated in the literature for significant bone defect. According to Pogrel et al. [27], the fibula should be used for a minimal bone defect of $9 \mathrm{~cm}$. Indeed, below $3 \mathrm{~cm}$, it is recommended either a shortening-re-lengthening, or a cancellous graft which may be collected from the iliac crests [14]. The shortening-re-lengthening technique is in fact only possible in the tibia, femur or humerus. In addition, there is no age limit found in the literature with regard to fibula transfers. Pedicled fibula transfers are indicated to the lower limb while free transfers are indicated to the upper limb [14]. These fibula transfers can be used in emergency or in the secondary management of bone loss as part of Orthopedic Damage Control [14]. Our case illustrates one of its indications in the management of a bone defect after sequestrectomy for chronic osteomyelitis. Masquelet [13] [34] in France proposed it as an alternative in the second step of management in bone defect, after placement of a cement spacer in his induced membrane technique. Isolated bone transfer is the most widely used in orthopedics-traumatology [17]. It is rarely vascularized graft in the treatment of distal leg bone defect (with an inverted pedicle), or in proximal tibia defect as well as of the distal femur one (with then a direct pedicle). In fact, it is almost always used as a free transfer in traumatology, in the reconstruction of any bone loss at the upper or lower limb (recent fractures, pseudarthrosis, etc.).

The bone defect reconstruction in the upper limb is essential to save its function. While the humerus could tolerate bone shortening, both bones in the forearm require respect for their length in order to maintain prono-suppination. We used a free non-vascularized fibula transfer in our little girl. The use of 
non-vascularized free fibula in upper limb bone defects is a good indication. Indeed, whether it is the humerus, the radius or the ulna, the diameter of the transposed fibula is quite close to the structure to be reconstructed. Adani et al. [38] reconstructed 13 patients at the level of the humerus using a free fibula. Nine consolidations took place straight away, and three additional bone grafts were necessary. For them, fibula transfer has the advantages of being able to provide a solid, rectilinear and bi-cortical bone flap up to $25-30 \mathrm{~cm}$; providing a graft from a bone which has at the same time segmental intraosseous and cutaneo-muscular vascularization that allows the realization of segmental osteotomies; and allowing two teams simultaneous work on a patient, the donor sit being distant from that of the recipient. Kerfant et al. [39] used a free non-vascularized fibula graft in five multi-operated patients with aseptic nonunion of the humerus. Radiological ossification of the graft was obtained in less than 6 months. These authors recommend free transfer of non-vascularized fibula if conventional humeral methods such as compression plates, nailing, and conventional bone grafts have failed.

Studies on dogs [40] have shown that non-vascularized grafts certainly presented more bone resorption than vascularized grafts. For Germain et al. [36], the vascularized fibula graft certainly has the same advantages as the non-vascularized graft but in addition, the vascularized fibula graft has no resorption and could thicken. Secondly, the vascularized fibula could be fractured but it spontaneously consolidates with simple orthopedic treatment. However, non-vascularized grafting has been preferred since 1991 with the addition of osteoconductive substances [24]. We did not have any osteoconductive substances like hydroxyapatite in our operating room. Performing a vascularized graft required the presence of microsurgical equipment that we did not have. Our case shows, however, that the absence of such technical possibilities does not exempt non-vascularized free grafts from good results.

The Papineau technique [41] uses cancellous grafts for defects smaller than 3 $\mathrm{cm}$ with deliberate delayed skin closure. We did not use the Papineau technique because in our 3-year-old girl, the iliac crests present growth cartilages and it was not possible to collect a sufficient quantity of spongy graft to reconstruct alone the $6 \mathrm{~cm}$ ulnar diaphyseal bone defect. According to some authors [14], this technique is long, source of prolonged hospital stay, and is no longer suited to the current demands of patients and surgeons.

The induced membrane technique with temporary interposition of an acrylic cement spacer to fill the loss of bone substance has been described by Masquelet in France [13] [34]. Acrylic cement was not available in our conditions and limited our therapeutic means, in particular not allowing us to effectively apply the Masquelet induced membrane technique. According to Masquelet et al. [13] [34], the induced membrane has the advantage to provide synovial tissue richly vascularized and endowed with osteoinductive properties after the first operative stage. These properties of the synovial tissue make it possible to obtain a corticalized bone in the presence of a cancellous graft. According to Zapppatera et al. 
[42], in France, in the event of a defect greater than $5 \mathrm{~cm}$, the induced membrane technique makes it possible to avoid the vascularized graft. In our opinion, this technique would therefore have been ideal for our 3-year-old girl and would have prevented us from reconstructing the defect sit which was filled with fibrosis, during the second operation. We did not have surgical cement to perform the Masquelet induced membrane technique. This material is expensive and beyond the reach of this family, which itself had to pay for the care of the child. Our case shows that in the absence of these resources in our limited conditions, therapeutic hope with a non-vascularized graft exists in children who are indeed endowed with good healing power and significant growth.

For Chang et al. [20], bone allografts have their specific complications like resorption and the risk of infection. Compared to allograft bone techniques which are not available in our regions and techniques using bone substitutes which are very expensive, non-vascularized fibula transfer is an easy technique, inexpensive for the family, always available and requiring neither microsurgical equipment nor knowledge of microsurgical techniques. Indeed, the advantages of free transfer of non-vascularized fibula are numerous: the fibula is a longitudinal cortical bone well adapted to the reconstruction of the long bones of the limbs [43]; dissection of the fibula is simple and allows two teams to work simultaneously; the technique preserves the limb and reconstructs its functions [44]; the fibula is a biological material; the ideal bone material is living, autologous.

In a three-year-old child, a $6 \mathrm{~cm}$ bone defect should be considered very important and the use of extreme forearm bone repair techniques as reported by Meziani et al. [24] or the Watson-Jones' single forearm bone would cause this young patient to lose prono-supination, which is serious. In children with a large diaphyseal bone defect in the forearm, the non-vascularized fibular graft would therefore do avoid the Watson-Jones technique.

Aronson et al. [18] reported good results with the Ilizarov technique for bone lengthening in diaphyseal bone defects. This technique has a promising future. However, it requires an external fixator which is expensive and not available actually in our conditions. In addition, the technique is very precise and must be mastered.

We achieved graft survival and rapid ossification in six weeks. Several authors [23] [26] reported $100 \%$ survival of the fibular graft, giving it a preferred choice over the iliac crest. We noted a bone callus forming in our patient 12 weeks after fibular transfer. For Chang et al. [20], the time to ossification was respectively 6 months in the absence of complications and 8 months in case of surgical revision or surgery in 2 stages. This duration is usual in reconstruction of pathological fractures in adults because, it involved 13 transfers to the lower limb and only one to the upper limb and an average age of 25 years. Radiological bone union was obtained in our child and the functional results are satisfactory. Germain et al. [36] also reported good results in the reconstruction of bone defect after carcinological resection in children after fibula transfer. However, they used microsurgical techniques for revascularization. At the time of this study, no teach- 
ing hospital in Togo had a surgical microscope or microsurgical instruments in the operating room for performing such techniques. The patient presented no functional discomfort in the actions of everyday life (washing, dressing, wearing a school satchel or for writing and drawing). The results that we obtained with the transfer of non-vascularized fibula are therefore good and definitive. It is therefore a recommendable method for the reconstruction of diaphyseal bone defect of the forearm under conditions of limited resources.

According to Le Nen et al. [17], the removal of the fibula does not cause any major functional sequelae in the lower limb. This was the case with our little girl. Cases of big toe extension deficits have been reported but with complete recovery within weeks [26]. The scar, even if it is long, is often discrete [17]. On the evolutionary level, our patient presented to the upper limb a right ulna varus, with a "carrying angle" of 8 degrees against 25 degrees on the left; an instability of the condylo-radial joint marked by subluxation of the right radial head maximum in pronation and reducing in supination.

Based on these findings, a subsequent indication for proximal metaphyseal ulnar osteotomy for valgization will be considered. This osteotomy can correct both the ulna varus and the subluxation of the radial head. However, the important thing here is the success of the transfer of non-vascularized fibula, which allowed the ulna to be reconstructed and to maintain satisfactory prono-supination without the occurrence of complications. Our technique therefore has a better prognosis than the Watson Jones technique (single-bone forearm technique) for which Meziani et al. [37] reported loss of pro-supination. The functional prognosis of fibular transfers for chronic osteomyelitis, cancer or gunshot wounds is encouraging in the literature [16] [29]. These transfers have in many cases prevented amputation [16] [28].

\section{Conclusion}

In the low income conditions that characterize our population; free transfer of non-vascularized fibula is an option to consider, in case of large diaphyseal bone defect in the forearm because it is simpler than other more sophisticated techniques. This technique made it possible to achieve good bone reconstruction and especially not to sacrifice prono-supination in a three-year-old girl who presented an ulnar diaphyseal bone defect of $6 \mathrm{~cm}$ after sequestrectomy for chronic osteomyelitis. The fibula has the advantage of its availability as an autologous graft; its shape, its length always sufficient. The very satisfactory results that we have reported with the free graft of non-vascularized fibula on the ulna are consistent with data in the literature. This technique shows great promise in the reconstruction of diaphyseal bone defects in children even under conditions of limited equipment.

\section{Formatting of Funding Sources}

This research did not receive any specific grant from funding agencies in the public, commercial, or not-for-profit sectors. 


\section{Conflicts of Interest}

The authors declare no conflicts of interest regarding the publication of this paper.

\section{References}

[1] Lazzarini, L., Mader, J.T. and Calhoun, J.H. (2004) Osteomyelitis in Long Bones. The Journal of Bone and Joint Surgery. American Volume, 86, 2305-2318. https://doi.org/10.2106/00004623-200410000-00028

[2] Yeargan, S.A., Nakasone, C.K., Shaieb, M.D., Montgomery, W.P. and Reinker, K.A. (2004) Treatment of Chronic Osteomyelitis in Children Resistant to Previous Therapy. Journal of Pediatric Orthopaedics, 24, 109-122. https://doi.org/10.1097/01241398-200401000-00021

[3] Mantero, E., Carbone, M., Calevo, M.G. and Boero, S. (2011) Diagnosis and Treatment of Pediatric Chronic Osteomyelitis in Developing Countries: Prospective Study of 96 Patients Treated in Kenya. Musculoskeletal Surgery, 95, 13-18. https://doi.org/10.1007/s12306-011-0104-0

[4] Onche, I.I. and Obiano, S.K. (2004) Chronic Osteomyelitis of Long Bones: Reasons for Delay in Presentation. Nigerian Journal of Medicine, 13, 355-358.

[5] Museru, L.M. and Mcharo, C.N. (2001) Chronic Osteomyelitis: A Continuing Orthopaedic Challenge in Developing Countries. International Orthopaedics, 25, 127-131. https://doi.org/10.1007/s002640100239

[6] Ikpeme, I.A., Ngim, N.E. and Ikpeme, A.A. (2010) Diagnosis and Treatment of Pyogenic Bone Infections. African Health Sciences, 10, 82-88.

[7] Lauschke, F.H. and Frey, C.T. (1994) Hematogenous Osteomyelitis in Infants and Children in the Northwestern Region of Namibia. Management and Two-Year Results. The Journal of Bone and Joint Surgery. American Volume, 76, 502-510. https://doi.org/10.2106/00004623-199404000-00004

[8] Stanley, C.M., Rutherford, G.W., Morshed, S., Coughlin, R.R. and Beyeza, T. (2010) Estimating the Healthcare Burden of Osteomyelitis in Uganda. Transactions of the Royal Society of Tropical Medicine and Hygiene, 104, 139-142.

https://doi.org/10.1016/j.trstmh.2009.05.014

[9] Beckles, V.L., Jones, H.W. and Harrison, W.J. (2010) Chronic Haematogenous Osteomyelitis in Children: A Retrospective Review of 167 Patients in Malawi. The Journal of Bone and Joint Surgery. British Volume, 92, 1138-1143. https://doi.org/10.1302/0301-620X.92B8.23413

[10] Tekou, H., Foly, A. and Akue, B. (2000) Le profil actuel des ostéomyélites hématogènes de l'enfant au centre hospitalier universitaire de Tokoin, Lomé, Togo: A propos de 145 cas. Médecine et Santé Tropicales, 60, 365-368.

[11] Akakpo-Numado, G.K., Gnassingbe, K., Boume, M.A., Songne, B. and Tekou, H. (2008) Bactériologie des ostéomyélites de l'enfant drépanocytaire au CHU de Tokoin (Togo): Tentative d'évaluation et thérapeutique. Cahiers Santé, 18, 67-70. https://doi.org/10.1684/san.2008.0106

[12] Wirbel, R. and Hermans, K. (2014) Surgical Treatment of Chronic Osteomyelitis in Children Admitted from Developing Countries. African Journal of Peadiatric Surgery, 11, 297-303. https://doi.org/10.4103/0189-6725.143133

[13] Masquelet, A.C., Sales de Gauzy, J., Bauer, T., Fabre, A., Fitoussi, F., Hannouche, D., et al. (2012) Reconstruction des pertes de substance osseuse diaphysaires d'origine traumatique. Stratégies, recommandations, perspectives. Mise au point. Revue de 
Chirurgie Orthopédique et Traumatologique, 98, 95-103.

https://doi.org/10.1016/j.rcot.2011.12.002

[14] Begue, T. (2013) Emergency Management of Severe Bone Losses in Limb Trauma Linked to Damage Control. e-mémoires de I Académie Nationale de Chirurgie, 12, 50-53.

[15] Kucukkaya, M., Kabukcuoglu, Y., Tezer, M. and Kuzgun, U. (2002) Management of Childhood Chronic Tibial Osteomyelitis with the Ilizarov Method. Journal of Pediatric Orthopaedics, 22, 632-637. https://doi.org/10.1097/01241398-200209000-00012

[16] Onuba, O. (1988) Chronic Osteomyelitis. Use of Ipsilateral Fibular Graft for Diaphyseal Defects of the Tibia. Tropical and Geographical Medicine, 40, 139-142.

[17] Le Nen, D., Dubrana, F., Hu, W., Prud'homme, M. and Lefevre, C. (2002) Fibula vascularisée. Techniques, indications en orthopédie et traumatologie. EMC Techniques chirurgicales. Orthopédie-Traumatologie. Elsevier SAS, Paris, 44-040.

[18] Aronson, J. (1997) Current Concept Review: Limb-Lengthening, Skeletal Reconstruction, and Bone Transport with the Ilizarov Method. The Journal of Bone and Joint Surgery. American Volume, 79, 1243-1258.

https://doi.org/10.2106/00004623-199708000-00019

[19] Delloye, C. (2007) Bone Allografts. What They Can Offer and What They Can Not. The Journal of Bone and Joint Surgery. British Volume, 89, 574-579.

https://doi.org/10.1302/0301-620X.89B5.19039

[20] Chang, D.W. and Weber, K.L. (2005) Use of Vascularized Fibula Bone Flap and Intercalary Allograft for Diaphyseal Reconstruction after Resection of Primary Extremity Bone Sarcomas. Plastic and Reconstructive Surgery, 116, 1918-1925. https://doi.org/10.1097/01.prs.0000189203.38204.d5

[21] Zaretski, A. and Amir, A. (2004) Free Fibular Long Bone Reconstruction Orthopedic Oncology: A Surgical Algorithm for Reconstructive Options. Plastic and Reconstructive Surgery, 113, 1989-2000. https://doi.org/10.1097/01.PRS.0000122213.82011.C5

[22] Friedrich, J.B., Moran, S.L., Bishop, A.T. and Shin, A.Y. (2009) Free Vascularized Fibula Grafts for Salvage of Failed Oncologic Long Bone Reconstruction and Pathologic Fractures. Microsurgery, 29, 385-392. https://doi.org/10.1002/micr.20624

[23] Hidalgo, D.A. (1989) Fibula Free Flap: A New Method of Mandible Reconstruction. Plastic and Reconstructive Surgery, 84, 71-79. https://doi.org/10.1097/00006534-198907000-00014

[24] Hidalgo, D.A. and Pusic, A.L. (2002) Free Flap Mandibular Reconstruction: A 10 Year Follow Up Study. Plastic and Reconstructive Surgery, 110, 438-449.

https://doi.org/10.1097/00006534-200208000-00010

[25] Lee, J.H., Kim, M.J. and Choi, W.S. (2004) Concomitant Reconstruction of Mandibular Basal and Alveolar Bone with a Free Fibular Flap. Journal of Oral and Maxillofacial Surgery, 33, 150-156. https://doi.org/10.1054/ijom.2003.0487

[26] Chen, C.M., Disa, J.J. and Lee, H.Y. (2007) Reconstruction of Extremity Long Bone Defects after Sarcoma Resection with Vascularized Fibula Flaps: A 10-Year Review.

Plastic and Reconstructive Surgery, 11, 915-924. https://doi.org/10.1097/01.prs.0000252306.72483.9b

[27] Pogrell, M.A., Podlesh, S., Anthony, J. and Alexander, J. (1997) A Comparison of Vascularized and Non-Vascularized Bone Grafts for Reconstruction of Mandibular Continuity Defects. Journal of Oral and Maxillofacial Surgery, 55, 1200-1206. https://doi.org/10.1016/S0278-2391(97)90165-8 
[28] Bahebeck, J., Ngowe, M., Mokom, P., Bob Oyono, J.-M., Moyo, S., Sosso, M. and Hoffmeyer, P. (2002) Le traitement de l'ostéomyélite chronique hématogène de l'enfant. Résultats préliminaires d'une série de 49 patients à Yaounde (Cameroun). Medecine et Hygiène, 60, 2381-2384.

[29] Ribault, L. and Lequellec, B. (1988) Excision diaphysaire totale avec greffe péronière secondaire chez l'enfant à propos d'un cas d'osteomyélite. Médecine et armées $A$, 16, 121-123.

[30] Kim, J.T., Ho, S.Y. and Kim, E.J. (2014) Autogenous Bone Fixation of the Fibular Flap in Recurrent Tibia Osteomyelitis. Journal of Plastic, Reconstructive \& Aesthetic Surgery, 67, 584-586. https://doi.org/10.1016/j.bjps.2013.11.001

[31] Lê Thua, T.H., Pham, D.N. and Boeck, W. (2014) Vascularized Fibular Transfer in Longstanding and Infected Large Bone Defects. Acta Orthopaedica Belgica, 80, 50-55.

[32] Pelissier, P., Casoli, V., Demiri, E., Martin, D. and Baudet, J. (2000) Soleus-Fibula Free Transfer in Lower Limb Reconstruction. Plastic and Reconstructive Surgery, 105, 567-573. https://doi.org/10.1097/00006534-200002000-00014

[33] Pelissier, P., Boireau, P. and Martin, D. (2003) Bone Reconstruction of the Lower Extremity; Complications and Outcomes. Plastic and Reconstructive Surgery, 111, 2223-2229. https://doi.org/10.1097/01.PRS.0000060116.21049.53

[34] Masquelet, A.C. (2008) Le concept de membrane induite pour la reconstruction des pertes de substance des os longs. E-mémoires de 1 Académie Nationale de Chirurgie, 7, 34-38.

[35] Oliveira, M.I., Ferreira, P.C. and Barbosa, R.F. (2009) Gunshot Upper Extremity Injury Reconstructed with a Fibula Osteoseptocutaneous Free Flap (Case Report). Techniques in Hand \& Upper Extremity Surgery, 13, 60-64. https://doi.org/10.1097/BTH.0b013e31818d1e1a

[36] Germain, M.A., Dubousset, J., Mascard, E. and Kalifa, C. (2000) Reconstruction with Vascularized Fibula after Resection for Tumoral Lesionsor Congenital Malformation of the Upper Limbin the Child. Bulletin de l'Académie Nationale de Médecine, 184, 1671-1686.

[37] Meziani, N., Yakoubi, M., Nait Djoudi, D. and Benbakouche, R. (2014) Pseudarthrose ancienne avec grande perte de substance osseuse du radius traitée par la technique de Watson Jones. A propos d'une observation. Chirurgie de la main, 33, 144-147. https://doi.org/10.1016/j.main.2014.02.001

[38] Adani, R., Delcroix, L., Innocenti, M., Tarallo, L. and Baccarani, A. (2008) Free Fibula Flap for Humerus Segmental Reconstruction: Report on 13 Cases. La Chirurgia Degli Organi di Movimento, 91, 21-26. https://doi.org/10.1007/s12306-007-0004-5

[39] Kerfant, N., Valenti, P., Kilinc, A.S. and Falcone, M.O. (2012) Free Vascularised Fibular Graftin Multi-Operated Patients for an Aseptic Non-Union of the Humerus with Segmental Defect: Surgical Techniqueand Results. Orthopaedics and Traumatology: Surgery and Research, 98, 603-607.

https://doi.org/10.1016/j.otsr.2012.03.013

[40] Taylor, G.I., Miller, G.D. and Ham, F.J. (1975) The Free Vascularized Bone Graft: A Clinical Extension of Microvascular Techniques. Plastic and Reconstructive Surgery, 55, 533-544. https://doi.org/10.1097/00006534-197505000-00002

[41] Papineau, L.J. (1973) L'excision-greffe avec fermeture retardéedélibérée dans l'ostéomyélite chronique. La Presse Médicale, 2, 2753-2755.

[42] Zappatera, T., Ghislandi, X., Adam, A., Huard, S., Gindraux, F., Gallinet, D., et al. (2011) Induced Membrane Technique for the Reconstruction of Bone Defects in 
Upper Limb. A Prospective Single Center Study of Nine Cases. Chirurgie de la Main, 30, 255-263. https://doi.org/10.1016/j.main.2011.06.005

[43] Organek, A.J., Klebuc, M.J. and Zuker, R.M. (2006) Indications and Outcomes of Free Tissue Transfer to the Lower Extremity in Children: Review. Journal of Reconstructive Microsurgery, 22, 173-181. https://doi.org/10.1055/s-2006-939963

[44] Yu, G.R., Yvan, F., Chang, S.M., Lineaweaver, W.C. and Zhang, F. (2005) Microsurgical Fibular Graft for Full-Length Radius Reconstruction after Giantcell Tumor Resection: A Case Report. Microsurgery, 25, 121-125.

https://doi.org/10.1002/micr.20091 